\title{
Allylboration of Aldehydes by Immobilized TRIP
}

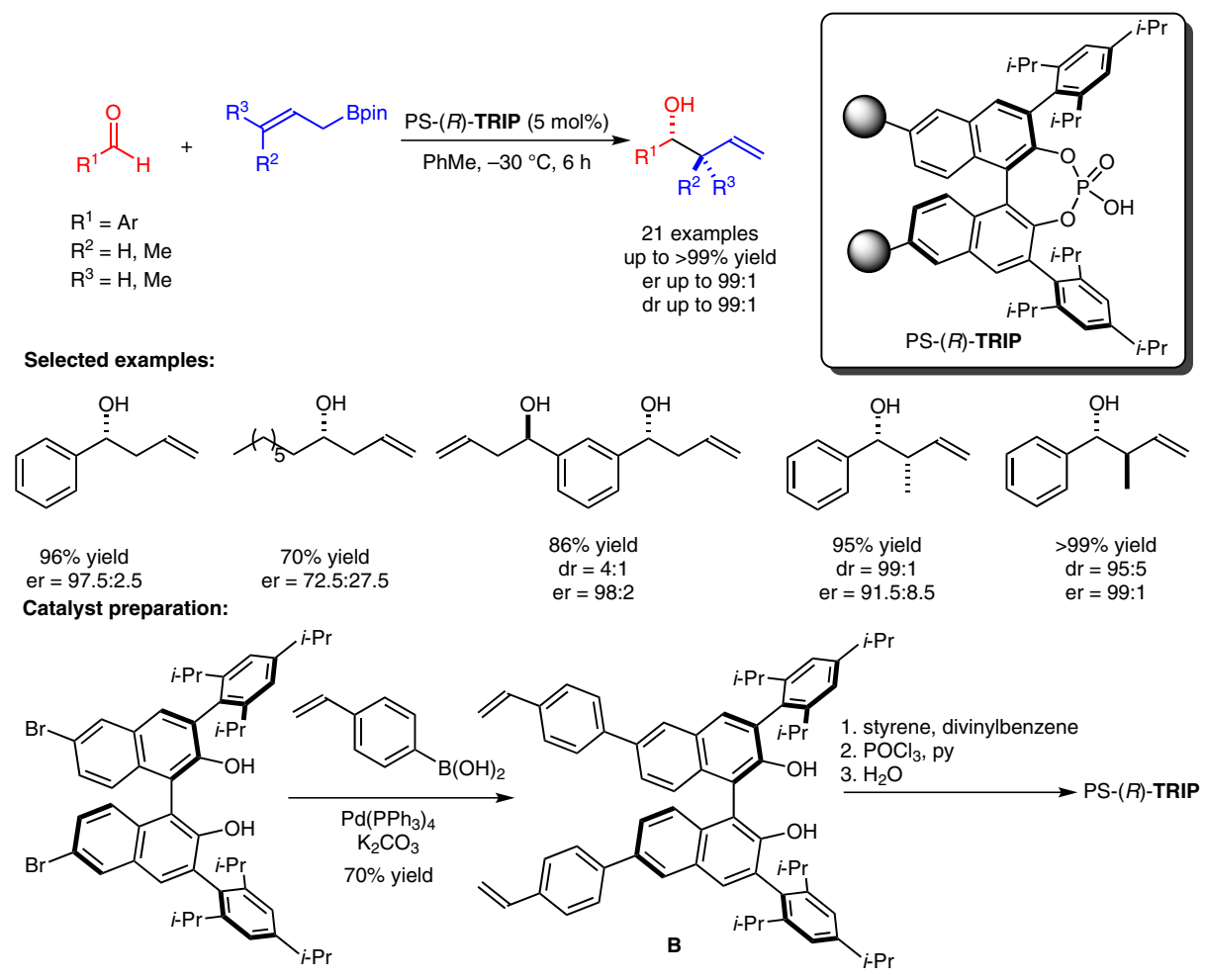

Significance: The Pericàs and Rodríguez-Escrich groups report an enantioselective allylboration of aldehydes catalyzed by polystyrene-immobilized TRIP phosphoric acid. The catalyst was prepared by copolymerization of the BINOL derivative $\mathbf{B}$ with styrene and divinylbenzene, resulting in a functionalization level of $0.20-0.23 \mathrm{mmol} / \mathrm{g}$. The desired homoallylic alcohols were obtained in generally good yields ( $\leq 99 \%)$, enantioselectivities (er $\leq 99: 1)$, and diastereoselectivities ( $d r \leq 99: 1$ ). Interestingly, the scope was explored by using a single sample of the catalyst regenerated by simply washing the resin with a solution of $\mathrm{HCl}$ in EtOAc.
Comment: Heterogeneous catalysts offer the advantages of easy recyclability and simplified workup procedures. Although methods for the immobilization of chiral phosphoric acids have been described, immobilization of the most successful acid (TRIP) had not previously been achieved. The authors applied their system to the continuousflow catalytic enantioselective allylation of benzaldehyde, giving the corresponding product in 92\% yield and an enantiomeric ration of 95.5:4.5 with a turnover number of 282 and a productivity of 2.22 $\mathrm{mmol} /\left(\mathrm{h} \cdot g_{\text {resin }}\right)$.

SYNFACTS Contributors: Benjamin List, Grigory A. Shevchenko 